\title{
1 Future projections of temperature-related excess out-of-hospital cardiac \\ 2 arrest under climate change scenarios in Japan
}

4 Daisuke Onozuka, $\mathrm{PhD}^{1,2}$, Antonio Gasparrini, $\mathrm{PhD}^{3,4}$, Francesco Sera, $\mathrm{MSc}^{3}$, Masahiro

5 Hashizume, $\mathrm{MD}, \mathrm{PhD}^{5}$, Yasushi Honda, $\mathrm{MD}, \mathrm{PhD}^{6}$

$7 \quad{ }^{1}$ Department of Preventive Medicine and Epidemiologic Informatics, National Cerebral and

8 Cardiovascular Center Research Institute, Osaka, Japan

$9 \quad{ }^{2}$ Department of Health Communication, Kyushu University Graduate School of Medical

10 Sciences, Fukuoka, Japan

$11{ }^{3}$ Department of Public Health, Environments and Society, London School of Hygiene \&

12 Tropical Medicine, London, UK

$13{ }^{4}$ Centre for Statistical Methodology, London School of Hygiene \& Tropical Medicine, London,

14 UK

$15{ }^{5}$ Department of Pediatric Infectious Diseases, Institute of Tropical Medicine, Nagasaki

16 University, Nagasaki, Japan

$17{ }^{6}$ Faculty of Health and Sport Sciences, University of Tsukuba, Tsukuba, Japan

19 Address for Correspondence:

20 Daisuke Onozuka, PhD

21 Department of Preventive Medicine and Epidemiologic Informatics

22 National Cerebral and Cardiovascular Center Research Institute

23 5-7-1 Fujishirodai, Suita, Osaka 565-8565, Japan 
24 Tel.: +81-6-6833-5012

25 Fax: +81-6-6872-8091

26 E-mail: onozukad@ncvc.go.jp

27

28 Running head: Projections of temperature-related excess OHCA

29 Keywords: Cardiac arrest; Climate change; Excess morbidity; Sudden death; Temperature

30 Word count for abstract: 253

31 Word count for text: 3,549 


\section{Abstract}

33 Background: Recent studies have reported associations between global climate change and

34 mortality. However, future projections of temperature-related out-of-hospital cardiac arrest

35 (OHCA) have not been thoroughly evaluated. Thus, we aimed to project temperature-related 36 morbidity for OHCA concomitant with climate change.

37 Methods: We collected national registry data on all OHCA cases reported in 2005-2015 from all

3847 Japanese prefectures. We used a two-stage time series analysis to estimate temperature-

39 OHCA relationships. Time series of current and future daily mean temperature variations were

40 constructed according to four climate change scenarios of representative concentration pathways

41 (RCPs) using five general circulation models. We projected excess morbidity for heat and cold

42 and the net change in 1990-2099 for each climate change scenario using the assumption of no

43 adaptation or population changes.

44 Results: During the study period, 739,717 OHCAs of presumed cardiac origin were reported.

45 Net decreases in temperature-related excess morbidity were observed under higher emission

46 scenarios. The net change in 2090-2099 compared with 2010-2019 was -0.8\% (95\% empirical

47 confidence interval $[\mathrm{eCI}]:-1.9,0.1)$ for a mild emission scenario (RCP2.6), $-2.6 \%(95 \%$ eCI: -

$484.4,-0.8)$ for a stabilization scenario (RCP4.5), -3.4\% (95\% eCI: -5.7, -1.0) for a stabilization

49 scenario (RCP6.0), and -4.2\% (95\% eCI: -8.3, -0.1) for an extreme emission scenario (RCP8.5).

50 Conclusions: Our study indicates that Japan is projected to experience a substantial net

51 reduction in OHCAs in higher-emission scenarios. The decrease in risk is limited to a specific

52 morbidity cause, and a broader assessment within climate change scenarios should consider other

53 direct and indirect impacts. 
INTRODUCTION

Climate change is widely recognized as the most significant global health threat of the

21 st century, and tackling climate change could be the greatest global health opportunity (Watts

59 et al., 2015). The fifth Intergovernmental Panel on Climate Change (IPCC) report indicates that

60 high-end emissions scenarios project increases in global mean temperatures of between 2.6 and

$614.8^{\circ} \mathrm{C}$ by the end of the century (Pachauri et al., 2014). While a number of important human

62 diseases have been associated with shifts in climate, a lack of long-term, high-quality data and a

63 significant influence from socio-economic factors has led to some uncertainty in attributing any

64 increase or re-emergence of diseases to climate change (Patz et al., 2005). Recent studies have

65 shown that climate change has the potential to substantially increase temperature-related

66 mortality (Benmarhnia et al., 2014; Gasparrini et al., 2017; Hajat et al., 2014; Lee and Kim,

67 2016). However, the future impact of health threats arising from climate change can differ quite

68 significantly among diseases (Watts et al., 2015), and the impacts of climate change on

69 morbidity has not been thoroughly evaluated.

70 Sudden cardiac arrest is a major contributor to morbidity and mortality in the general

71 population, and accounts for almost 10-20\% of all deaths (Field et al., 2010). In particular, out-

72 of-hospital cardiac arrest (OHCA) is characterized by unexpected collapse due to a cardiac

73 disorder (Tian and Qiu, 2017). Although resuscitation rates are generally improving globally,

74 OHCA is a leading global cause of mortality (Nichol et al., 2008; Wissenberg et al., 2013).

75 Coronary artery disease is a key contributor to sudden cardiac arrest (Mozaffarian et al., 2015).

76 However, OHCA is multifactorial and complex in nature (Patz et al., 2005). Several studies that

77 aimed to quantify the burden of OHCA have had difficulty accurately accounting for potential

78 adaptation to climate change over time and place. Meanwhile, OHCA remains a prime and 
79 significant cause of death due to cardiovascular diseases. It is therefore paramount to focus on

80 OHCA to improve prediction estimates and to aid in prioritizing mitigation and adaptation

81 policies to climate change in the future.

82 As concerns associated with climate change have increased over the past few decades,

83 there has been emerging evidence supporting a relationship between OHCA and environmental

84 factors such as extreme weather conditions like heat and cold events (Onozuka and Hagihara,

85 2017a; Onozuka and Hagihara, 2017c; Onozuka and Hagihara, 2017e). For example, several

86 studies have shown a positive association between extremely high and low temperatures and

87 OHCA risk (Onozuka and Hagihara, 2017a). Moreover, recent studies have also shown that the

88 majority of temperature-related OHCA burden is attributable to low temperatures, and that the

89 effect of extreme temperatures is substantially lower than that of moderate temperatures

90 (Onozuka and Hagihara, 2017c). These findings suggest that climate change may raise heat-

91 related morbidity, while concomitantly reducing cold-related morbidity. However, future

92 projections of temperature-related excess morbidity due to OHCA according to climate change

93 scenarios have not been studied. Furthermore, the degree to which the anticipated reduction in

94 cold-related morbidity can counter the rise in heat-related morbidity remains to be determined.

95 This data will be important for the development of coordinated and evidence-based climate

96 change and public health methods to prevent climate change-related OHCA.

97 Here, we aimed to project the future impact of climate change on temperature-attributable

98 OHCA morbidity using Japanese national registry data from all OHCA cases reported in 2005-

992015 that were assumed to be of cardiac origin.

100

101 METHODS 


\section{Study design}

103 We used the same study design and statistical framework described in detail elsewhere

104 (Gasparrini et al., 2017; Vicedo-Cabrera et al., 2019). Briefly, we used a two-stage time-series

105 analysis to predict the association between temperature and daily morbidity due to OHCA in all

10647 Japanese prefectures. Additionally, we acquired daily mean temperature time-series according

107 to climate change scenarios of the four representative concentration pathways (RCPs), RCP2.6,

108 RCP4.5, RCP6.0, and RCP8.5. We merged these data to estimate future projections of excess

109 morbidity attributable to temperature.

110

\section{Ethics approval}

112 This study was approved by the Ethics Committee of the Kyushu University Graduate

113 School of Medical Sciences. Written informed consent was not required because of the

114 retrospective observational nature of this study, which used national registry data, and the fact

115 that enrolled subjects were deidentified by the Fire and Disaster Management Agency (FDMA).

\section{Data sources}

118 We used national registry data from the FDMA regarding all OHCA cases that were 119 reported from 2005 to 2015 in all 47 Japanese prefectures. According to Japan's Fire Service Act, 120 municipal government-enlisted emergency medical services (EMSs) are provided at around 800

121 fire stations and related dispatch centers across Japan. Given that EMS providers do not have the 122 authority to terminate resuscitation in the field, all EMS-treated OHCA cases are transported to a

123 hospital. EMS personnel summarize each OHCA case in conjunction with the physician in

124 charge according to the standardized Utstein-style reporting guidelines for cardiac arrest 
125 (Hagihara et al., 2012). The physician in charge together with the EMS personnel clinically

126 ascertained the cause of cardiac arrest (i.e., presumed cardiac or non-cardiac). All arrests were

127 considered to be of cardiac origin unless the cause was drowning, trauma, drug overdose,

128 exsanguination, asphyxia, or any other obvious non-cardiac cause. Fire stations with dispatch

129 centers in the 47 prefectures send their data to the FDMA, where the data is incorporated into the

130 national registry system on the FDMA database server. According to the Fire Service Act, all

131 OHCA cases must be registered in Japan. The national registry data for OHCA cases is therefore

132 regarded as comprehensive across the country. The FDMA's computer system was used to check

133 and validate the data for consistency (Kitamura et al., 2016). We included all patients that

134 experienced an OHCA of presumed cardiac origin, and we extracted the daily time-series of

135 OHCA cases from the national registry database.

136 We also acquired data on daily mean temperatures from the Japan Meteorological

137 Agency. Data from one weather station positioned in an urban area of the capital city was used as

138 representative data for the region for each prefecture because these were synoptic climatological

139 stations and intended to capture macro-scale weather for each prefecture. Daily mean

140 temperatures were computed as 24-hour averages according to hourly measurements. Daily mean

141 temperature was used as the main exposure index as it is indicative of exposure throughout the

142 day and can be readily interpreted for decision-making purposes (Guo et al., 2011; Guo et al., 143 2014).

\section{Scenario models}

146 We estimated the projections of future temperature-related OHCA under four climate 147 change scenarios using models of climate change and morbidity. First, we acquired time series 
data for daily mean temperatures according to four climate change scenarios of representative concentration pathways (RCPs) (van Vuuren et al., 2011a). The four RCPs (RCP2.6, RCP4.5, RCP6.0, and RCP8.5) present rising greenhouse gas concentration trajectories: RCP2.6 models a mild emission scenario in which peaks in radiative forcing at $\sim 3 \mathrm{~W} / \mathrm{m}^{2}$ before 2100 and then declines to $2.6 \mathrm{~W} / \mathrm{m}^{2}$ by $2100, \mathrm{RCP} 4.5$ models a stabilization scenario in which total radiative forcing is stabilized shortly after 2100 , without overshooting the long-run radiative forcing target level of $4.5 \mathrm{~W} / \mathrm{m}^{2}$, RCP6 models a stabilization scenario in which total radiative forcing is stabilized shortly after 2100 , without overshoot pathway to $6 \mathrm{~W} / \mathrm{m}^{2}$, by the application of a range of technologies and strategies for reducing greenhouse gas emissions, and RCP8.5 models an extreme emission scenario in which rising radiative forcing pathway leading to $8.5 \mathrm{~W} / \mathrm{m}^{2}$ by 2100 (van Vuuren et al., 2011a). The RCPs were generated following collaborations between integrated assessment modelers, climate modelers, terrestrial ecosystem modelers, and emission inventory experts (van Vuuren et al., 2011a). Future projections of daily mean temperatures under each RCP were then developed using general circulation models (GCMs) (Warszawski et al., 2014). GCMs were designed to enable the quantification of representation of historical, current, and projected climate consistent with scenarios of increases in radiative atmospheric forces, summarized by RCPs. The Inter-Sectoral Impact Model Intercomparison Project (ISIMIP) database includes daily temperature series for each RCP scenario of five GCMs (GFDLESM2M (Dunne et al., 2012; Dunne et al., 2013), HadGEM2-ES (Jones et al., 2011), IPSLCM5A-LR (Mignot and Bony, 2013), MIROC-ESM-CHEM (Watanabe et al., 2011), and NorESMI-M (Bentsen et al., 2013; Iversen et al., 2013)), and these five GCMs were regarded as the representatives of the full range of projections of future climate based on the current existing scientific literature within the fifth phase of the Climate Model Intercomparison Project (CMIP5) 
171 models (Taylor et al., 2012; Warszawski et al., 2014). The ISI-MIP database

172 (https://www.isimip.org/) contains time series of daily mean temperatures for historical (1960-

173 2005) and projected (2006-2099) periods, which are bias-corrected and downscaled to

$1740.5^{\circ} \times 0.5^{\circ}$ spatial resolution (Warszawski et al., 2014). GCMs were generated by considering

175 the difference in climate change impact at varying levels of global warming according to the four

176 RCPs to produce the highest and lowest end-of-century forcings (Warszawski et al., 2014).

177 When the modelled daily temperature series are applied to exposure-response relationships

178 estimated using observed daily time series for daily mean temperature, deviations between the

179 modelled and observed daily temperature series may produce biased results in the impact

180 projections. Therefore, the modelled daily temperature series were corrected using the bias-

181 correction method, which recalibrated using the monthly mean and the daily variability around

182 the monthly mean of observed daily temperature series (Hempel et al., 2013). We calculated the

183 projected daily time series of OHCAs as the mean observed count for each day of the year, and

184 repeated this across the projection period (1990-2099).

186 Statistical analysis

187 Estimation of exposure-response relationships

188 We used two-stage time series analysis to predict the prefecture-specific non-linear lag 189 impact of temperature on OHCA, as described previously (Gasparrini et al., 2016; Onozuka and 190 Hagihara, 2017c; Zhang et al., 2019; Zhang et al., 2017). Briefly, first, we investigated the 191 association between temperature and OHCA in individual prefectures using a time-series quasi192 Poisson regression model combined with a distributed lag non-linear model, adjusting for season, 193 long-term trends, and day of the week. We examined lag periods of up to 21 days to consider the 
194 delayed impact of low temperatures. Second, we combined prefecture-specific estimates using

195 multivariate meta-regression models to predict the nationwide non-linear temperature-OHCA

196 association. This method has been described in detail elsewhere (Gasparrini et al., 2017; Vicedo-

197 Cabrera et al., 2019).

199 Projection of the effect on morbidity

200 We projected excess morbidity due to temperature using the daily temperature and

201 morbidity time-series model according to the assumption of no adaptation or population changes,

202 as described previously (Gasparrini et al., 2016; Onozuka and Hagihara, 2017c). Briefly, we

203 determined the minimum morbidity temperature using the lowest value of the total cumulative

204 relative risk between temperature and OHCA. We used the minimum morbidity temperature as a

205 reference to compute the attributable risk by re-centering the natural cubic spline. This value was

206 regarded as the optimal temperature. The total attributable number of OHCAs as a result of non-

207 optimal temperatures was computed as the sum of contributions from all days in the series. The

208 ratio of this value to the total number of OHCAs was regarded as the total attributable fraction.

209 Components that were attributable to low and high temperatures were computed by accumulating

210 the subsets corresponding to days with temperatures below or above the minimum morbidity

211 temperature. First, we estimated the excess morbidity for each prefecture and combinations of

212 GCMs and RCPs. Second, we computed attributable fractions as GCM-ensemble means

213 according to decade and RCP using the respective total number of OHCAs as the denominator.

214 Monte Carlo simulations were used to compute empirical confidence intervals (eCIs), calculate

215 the uncertainty in both the estimated exposure-lag-response association and climate projections 
216 among GCMs. Details of this method were described previously (Gasparrini et al., 2017; Vicedo-

217 Cabrera et al., 2019).

218 For sensitivity analysis, modeling selections were tested by controlling for different

219 degrees of freedom for time trends (6 and 10 degrees of freedom per year), by choosing different

220 lags (14 and 28 days), and by including or excluding different confounding factors (relative

221 humidity, public holiday, and day of the week). All statistical analyses were conducted using R

222 3.5.0 (R Core Team, R Foundation for Statistical Computing, Vienna, Austria), specifically using

223 the dlnm and mvmeta packages.

224

225 RESULTS

226 A total of 739,717 OHCA cases of presumed cardiac origin were registered between

227 January 1, 2005 and December 31, 2015 in the 47 prefectures of Japan. The daily mean

228 temperature was $15.6^{\circ} \mathrm{C}$, and the prefecture-specific daily mean temperature ranged from $9.4^{\circ} \mathrm{C}$

229 in Hokkaido Prefecture to $17.4^{\circ} \mathrm{C}$ in Fukuoka Prefecture (Figure 1, Figure S1 and Table S1 in the

230 Supplement).

231 The variation in the mean temperature in the current period (2010-19) and the projected

232 increase at the end of the 21st century (2090-99) in the four RCP scenarios in Japan are shown in

233 Figure 2 and Table 1. We projected a steep rise in mean temperatures under high-end emission

234 scenarios (RCP6.0 and RCP8.5); however, this rise slowed or tended to be reduced after a

235 number of decades under climate change scenarios that assume greenhouse gas mitigation

236 policies (RCP2.6 and RCP4.5) (Figure 2 and Figure S2 in the Supplement). By the end of the

23721 st century, a drop in greenhouse gas emissions may avert warming in Japan, with a mean rise

238 in temperature of $0.6^{\circ} \mathrm{C}$ (range: $0.4-0.9$ ) under RCP2.6 compared to $4.0^{\circ} \mathrm{C}$ (range: $3.0-4.9$ ) 
239 under RCP8.5. The respective data from each prefecture are shown in Figures S2 and S3 in the

240 Supplement.

241 Projected trends in heat- and cold-related excess morbidity according to three RCPs in

242 Japan are summarized in Figure 3 and Table 1. Our findings showed a common pattern of a

243 reduction in cold-related morbidity and mild rise in excess morbidity due to heat across the

244 scenarios. The projected slopes were steeper under RCP8.5, while the trends were shallower

245 throughout the 21st century under scenarios that assume mitigation strategies. Cold-related

246 excess morbidity is projected to be reduced from $19.9 \%$ (95\% eCI: $-0.1,33.4$ ) in $2010-2019$ to

$24713.8 \%$ (95\% eCI: -2.5, 25.5) in 2090-2099 under scenarios of intense warming (RCP8.5), and

248 there is a large degree of uncertainty for cold-related morbidity. In contrast, heat-related excess

249 morbidity is projected to rise from $0.4 \%$ (95\% eCI: $0.1,0.6)$ to $2.4 \%$ (95\% eCI: $0.5,4.2)$ across

250 the same period and conditions. The respective data from each prefecture are shown in Figures

251 S4 and S5 in the Supplement.

252 Temporal changes in excess morbidity under three different RCPs in Japan are

253 summarized in Figure 4 and Table 3. There was a marked net reduction in excess morbidity,

254 ranging from $-0.8 \%(95 \%$ eCI $-1.9,0.1)$ under RCP2.6 to $-4.2 \%$ (95\% eCI $-8.3,-0.1)$ under

255 RCP8.5. The respective data from each prefecture are shown in Figure S6 and Tables S2-S5 in

256 the Supplement.

257 The sensitivity analysis revealed that varying the choice of model had little effect on the 258 estimates (Supplementary Table S6). 
We investigated projections of the nationwide impact of temperature on OHCA in Japan

262 according to different climate change scenarios using recently developed study designs and

263 advanced statistical methods. We found that temperature-related excess morbidity is expected to

264 be reduced under higher emission scenarios. To our knowledge, our study is the first to

265 investigate the possible impact of temperature changes according to climate change scenarios on

266 OHCA. Our findings indicate that climate change may have positive effects on OHCA.

267 Our study shows that climate change may possibly result in a marked reduction in

268 temperature-related OHCA. We also found a steep reduction in cold-related excess morbidity

269 under higher emission scenarios of global warming, and a small increase in heat-related excess

270 morbidity. These findings agree with those of recent studies, which predict that lower intensity

271 warming and bigger reductions in cold-related excess mortality could stimulate a minimal

272 negative net effect in temperate areas, including Japan (Gasparrini et al., 2017). Moreover,

273 temperature-related mortality due to acute ischemic heart disease is projected to remain stable

274 over time under changing climate conditions in China (Li et al., 2018). However, another study

275 in China projected that temperature-related cardiovascular disease mortality will increase under

276 different RCP scenarios (Zhang et al., 2018). These findings indicate that ambient temperatures

277 may impact the various subtypes of cardiovascular diseases in differing ways (Lin et al., 2009).

278 Further, the mechanisms governing cardiac events involve multiple factors and complex

279 interactions (Woodhouse et al., 1994). Although the physiological mechanism underlying

280 temperature-related cardiovascular events remains to be elucidated, our results emphasize the

281 need for additional studies on the projections of temperature-related excess morbidity for

282 cardiovascular diseases. 
The net reduction in OHCA as a result of global warming may be explained by several

284 mechanisms. First, increasing temperature due to global warming may reduce health problems

285 related to low temperatures, which can lead to offset the increase in morbidity by high

286 temperatures. A recent study has shown that, although both high and low temperatures are

287 responsible for OHCA burden, most OHCA cases are attributable to low temperatures (Onozuka

288 and Hagihara, 2017c). Regarding low temperature-related health problems, recent studies have

289 indicated that circulatory and coronary heart disease and ST-elevation myocardial infarction

290 (STEMI) mortality is increased with low temperatures (Schwartz et al., 2015). It is possible that

291 low temperatures trigger sympathetic stimulation and a rise in cardiac workload, which could

292 stress a person with severe coronary stenosis and/or advanced heart failure beyond their

293 compensation threshold (Izzo et al., 1990; Schwartz et al., 2015; Wolf et al., 2009). Second, low

294 temperatures may contribute to the cardiovascular stress response by increasing blood viscosity,

295 changing heart rate variability, and impacting inflammatory responses (Keatinge et al., 1986).

296 Low temperature periods have been linked to high excess risk of heart failure, arrhythmia, and

297 atrial fibrillation (Medina-Ramon et al., 2006). Low temperatures raise sympathetic tone, blood

298 pressure, vascular resistance, fibrinogen level, platelet count, some clotting factors, and blood

299 viscosity, which can raise the risk of plaque rupture, thrombosis, and STEMI mortality (Izzo et

300 al., 1990; Schwartz et al., 2015; Wolf et al., 2009). Furthermore, those with reduced vitamin D

301 levels are vulnerable to sudden cardiac death during winter, suggesting that increasing vitamin D

302 levels by adequate sun exposure in the winter months may be significant for decreasing sudden

303 cardiac death (Deo et al., 2011; Drechsler et al., 2010; Giovannucci et al., 2008; Onozuka and

304 Hagihara, 2017b; Onozuka and Hagihara, 2017d). Our findings are therefore physiologically 
305 plausible and suggest that climate change according to different levels of future global warming 306 may markedly reduce OHCA.

307 Our findings suggest that variations in temperature-related excess OHCA are proportional 308 to the degree of global warming under each of the RCP emission scenarios. We found that the 309 largest net reduction in excess morbidity was projected under RCP8.5, which assumes very high

310 greenhouse gas emissions (Pachauri et al., 2014). In contrast, the net reduction in excess

311 morbidity is lower under RCP2.6, which assumes a limited increase in global mean temperatures

312 of $2^{\circ} \mathrm{C}$ following climate change adaptation and mitigation policies (van Vuuren et al., 2011b).

313 Although recent studies have reported the negative impacts of climate change on mortality

314 (Gasparrini et al., 2017), there may be inconsistencies in the direction and magnitude of the

315 impacts on mortality and morbidity due to climate change. Our results emphasize the importance

316 of further investigation into projections of global warming and the associated impacts on

317 mortality and morbidity due to different causes.

318 Our results have practical implications for refining or adjusting estimates for climate 319 change-related OHCA in future public health policies. Our study projects a largest decrease in 320 net excess OHCA morbidity due to climate change under high-emission scenarios. The majority

321 of the excess morbidity was attributable to low temperatures, while heat was only associated 322 with a small fraction of excess morbidity. Additionally, the reduction in temperature-related net 323 excess morbidity is expected to be significant in scenarios of high greenhouse gas emissions.

324 These findings are important for the development of disease-specific public health policies, and 325 for informing the ongoing international discussion on the health impacts of climate change.

326 There were several limitations in our study. First, while our projections of temperature-

327 OHCA relationships according to future warming scenarios enabled isolation of the effects of 
328 climate change, they did not account for important factors such as demographic changes and

329 adaptation (Arbuthnott et al., 2016; Hajat et al., 2014; Nordio et al., 2015; O’Neill et al., 2014).

330 Especially, since a recent study suggested that gender and age are vulnerability factors for the

331 effect of temperature on OHCA (Onozuka and Hagihara, 2017c), demographic and adaptation

332 changes in the future can alter the impact of climate change on OHCA. Therefore, our results

333 should not be interpreted as predictions of future excess morbidity but rather possible outcomes

334 under well-defined but hypothetical scenarios. Second, our projections of temperature-related

335 excess morbidity are subject to considerable uncertainty, especially those associated with the net

336 impact, because of both variability in the climate models and imprecision in the predicted

337 exposure-response correlation (Benmarhnia et al., 2014). Third, we used available outdoor

338 monitoring data from one representative weather station to represent population exposure to the

339 mean temperature. Thus, exposure measurement bias and misclassification should not be

340 ignored. These factors might affect the interpretation of our findings, and additional studies using

341 more precise modeling methods are required to resolve these issues.

342 In summary, our study indicates that Japan is projected to experience a substantial net

343 reduction in OHCA under higher-emission scenarios. The decrease in risk is limited to a specific

344 morbidity cause, and a broader assessment of cardiovascular disease morbidity within climate

345 change scenarios should consider other direct and indirect impacts.

347 Acknowledgments

348 We thank Manabu Hasegawa, Takuya Ishizaka, and Kenji Nakanishi for their assistance with

349 acquiring data from the Fire and Disaster Management Agency of the Ministry of Internal

350 Affairs and Communications, Japan. 


\section{Financial Disclosure}

353 This work was supported by the Japan Society for the Promotion of Science (JSPS) KAKENHI

354 Grant Numbers 15K08714, 16H05247, 18K11666, and 19H03900; the Medical Research

355 Council UK (Grant ID: MR/M022625/1); and the Natural Environment Research Council UK

356 (Grant ID: NE/R009384/1). The funding sources had no role in the study design, data collection,

357 data analysis, data interpretation, or preparation of the manuscript.

\section{Author Contributions}

360 DO made substantial contributions to conception and design, did the statistical analysis, took the 361 lead in drafting the manuscript, and interpreting the results. DO, AG, and FS developed the 362 statistical methods. $\mathrm{MH}$ and $\mathrm{YH}$ provided data and substantial scientific input in interpreting the 363 results and drafting the manuscript. All gave final approval and agree to be accountable for all 364 aspects of work ensuring integrity and accuracy.

\section{Competing Interests}

367 The authors declare that they have no competing interests. 


\section{References}

Arbuthnott K, Hajat S, Heaviside C, Vardoulakis S. Changes in population susceptibility to heat and cold over time: assessing adaptation to climate change. Environ Health 2016; 15 Suppl 1: 33.

Benmarhnia T, Sottile MF, Plante C, Brand A, Casati B, Fournier M, et al. Variability in temperature-related mortality projections under climate change. Environ Health Perspect 2014; 122: 1293-8.

Bentsen M, Bethke I, Debernard JB, Iversen T, Kirkevåg A, Seland Ø, et al. The Norwegian Earth System Model, NorESM1-M - Part 1: Description and basic evaluation of the physical climate. Geosci. Model Dev. 2013; 6: 687-720.

Deo R, Katz R, Shlipak MG, Sotoodehnia N, Psaty BM, Sarnak MJ, et al. Vitamin D, parathyroid hormone, and sudden cardiac death: results from the Cardiovascular Health Study. Hypertension 2011; 58: 1021-8.

Drechsler C, Pilz S, Obermayer-Pietsch B, Verduijn M, Tomaschitz A, Krane V, et al. Vitamin D deficiency is associated with sudden cardiac death, combined cardiovascular events, and mortality in haemodialysis patients. Eur Heart J 2010; 31: 2253-61.

Dunne JP, John JG, Adcroft AJ, Griffies SM, Hallberg RW, Shevliakova E, et al. GFDL's ESM2 Global Coupled Climate-Carbon Earth System Models. Part I: Physical Formulation and Baseline Simulation Characteristics. Journal of Climate 2012; 25: 6646-6665.

Dunne JP, John JG, Shevliakova E, Stouffer RJ, Krasting JP, Malyshev SL, et al. GFDL's ESM2 Global Coupled Climate-Carbon Earth System Models. Part II: Carbon System Formulation and Baseline Simulation Characteristics. Journal of Climate 2013; 26: 22472267. 
392

393

394

395

396

397

398

399

400

401

402

403

404

405

406

407

408

409

410

411

412

413

414
Field JM, Hazinski MF, Sayre MR, Chameides L, Schexnayder SM, Hemphill R, et al. Part 1: executive summary: 2010 American Heart Association Guidelines for Cardiopulmonary Resuscitation and Emergency Cardiovascular Care. Circulation 2010; 122: S640-56.

Gasparrini A, Guo Y, Hashizume M, Lavigne E, Tobias A, Zanobetti A, et al. Changes in Susceptibility to Heat During the Summer: A Multicountry Analysis. Am J Epidemiol 2016.

Gasparrini A, Guo Y, Sera F, Vicedo-Cabrera AM, Huber V, Tong S, et al. Projections of temperature-related excess mortality under climate change scenarios. Lancet Planet Health 2017; 1: e360-e367.

Giovannucci E, Liu Y, Hollis BW, Rimm EB. 25-hydroxyvitamin D and risk of myocardial infarction in men: a prospective study. Arch Intern Med 2008; 168: 1174-80.

Guo Y, Barnett AG, Pan X, Yu W, Tong S. The impact of temperature on mortality in Tianjin, China: a case-crossover design with a distributed lag nonlinear model. Environ Health Perspect 2011; 119: 1719-25.

Guo Y, Gasparrini A, Armstrong B, Li S, Tawatsupa B, Tobias A, et al. Global variation in the effects of ambient temperature on mortality: a systematic evaluation. Epidemiology 2014; 25: 781-9.

Hagihara A, Hasegawa M, Abe T, Nagata T, Wakata Y, Miyazaki S. Prehospital epinephrine use and survival among patients with out-of-hospital cardiac arrest. JAMA 2012; 307: 11618.

Hajat S, Vardoulakis S, Heaviside C, Eggen B. Climate change effects on human health: projections of temperature-related mortality for the UK during the 2020s, 2050s and 2080s. J Epidemiol Community Health 2014; 68: 641-8. 
415 Hempel S, Frieler K, Warszawski L, Schewe J, Piontek F. A trend-preserving bias correction 416 \&ndash; The ISI-MIP approach. Earth System Dynamics 2013; 4: 219-236.

417 Iversen T, Bentsen M, Bethke I, Debernard JB, Kirkevåg A, Seland $\varnothing$, et al. The Norwegian 418 Earth System Model, NorESM1-M - Part 2: Climate response and scenario projections. 419 Geosci. Model Dev. 2013; 6: 389-415.

420 Izzo JL, Jr., Larrabee PS, Sander E, Lillis LM. Hemodynamics of seasonal adaptation. Am J $421 \quad$ Hypertens 1990; 3: 405-7.

422 Jones CD, Hughes JK, Bellouin N, Hardiman SC, Jones GS, Knight J, et al. The HadGEM2-ES 423 implementation of CMIP5 centennial simulations. Geosci. Model Dev. 2011; 4: 543-570. 424 Keatinge WR, Coleshaw SR, Easton JC, Cotter F, Mattock MB, Chelliah R. Increased platelet 425 and red cell counts, blood viscosity, and plasma cholesterol levels during heat stress, and mortality from coronary and cerebral thrombosis. Am J Med 1986; 81: 795-800.

427 Kitamura T, Kiyohara K, Sakai T, Matsuyama T, Hatakeyama T, Shimamoto T, et al. Public428 Access Defibrillation and Out-of-Hospital Cardiac Arrest in Japan. N Engl J Med 2016; $429 \quad 375: 1649-1659$.

430 Lee JY, Kim H. Projection of future temperature-related mortality due to climate and 431 demographic changes. Environ Int 2016; 94: 489-494.

432 Li T, Horton RM, Bader DA, Liu F, Sun Q, Kinney PL. Long-term projections of temperature433 related mortality risks for ischemic stroke, hemorrhagic stroke, and acute ischemic heart 434 disease under changing climate in Beijing, China. Environ Int 2018; 112: 1-9.

435 Lin S, Luo M, Walker RJ, Liu X, Hwang SA, Chinery R. Extreme high temperatures and hospital 436 admissions for respiratory and cardiovascular diseases. Epidemiology 2009; 20: 738-46. 
437 Medina-Ramon M, Zanobetti A, Cavanagh DP, Schwartz J. Extreme temperatures and mortality: $438 \quad$ assessing effect modification by personal characteristics and specific cause of death in a 439 multi-city case-only analysis. Environ Health Perspect 2006; 114: 1331-6.

440 Mignot J, Bony S. Presentation and analysis of the IPSL and CNRM climate models used in $441 \quad$ CMIP5. Climate Dynamics 2013; 40: 2089-2089.

442 Mozaffarian D, Benjamin EJ, Go AS, Arnett DK, Blaha MJ, Cushman M, et al. Heart disease and 443 stroke statistics--2015 update: a report from the American Heart Association. Circulation 2015; 131: e29-322.

445 Nichol G, Thomas E, Callaway CW, Hedges J, Powell JL, Aufderheide TP, et al. Regional 446 variation in out-of-hospital cardiac arrest incidence and outcome. JAMA 2008; 300: 1423-31.

448 Nordio F, Zanobetti A, Colicino E, Kloog I, Schwartz J. Changing patterns of the temperaturemortality association by time and location in the US, and implications for climate change.

$450 \quad$ Environ Int 2015; 81: 80-6.

451 O’Neill BC, Kriegler E, Riahi K, Ebi KL, Hallegatte S, Carter TR, et al. A new scenario 452 framework for climate change research: the concept of shared socioeconomic pathways. $453 \quad$ Climatic Change 2014; 122: 387-400.

454 Onozuka D, Hagihara A. Extreme temperature and out-of-hospital cardiac arrest in Japan: A 455 nationwide, retrospective, observational study. Sci Total Environ 2017a; 575: 258-264. 456 Onozuka D, Hagihara A. Out-of-hospital cardiac arrest attributable to sunshine: a nationwide, 457 458 retrospective, observational study. Eur Heart J Qual Care Clin Outcomes 2017b; 3: 107113. Sci Rep 2017c; 7: 39538. 
461 Onozuka D, Hagihara A. Solar radiation and out-of-hospital cardiac arrest in Japan. Environ $462 \quad$ Pollut 2017d; 230: 46-52.

463 Onozuka D, Hagihara A. Spatiotemporal variation in heat-related out-of-hospital cardiac arrest 464 during the summer in Japan. Sci Total Environ 2017e; 583: 401-407.

465 Pachauri RK, Allen MR, Barros VR, Broome J, Cramer W, Christ R, et al. Climate change 2014:

466 synthesis report. Contribution of Working Groups I, II and III to the fifth assessment 467 report of the Intergovernmental Panel on Climate Change: IPCC, 2014.

468 Patz JA, Campbell-Lendrum D, Holloway T, Foley JA. Impact of regional climate change on 469 human health. Nature 2005; 438: 310-7.

470 Schwartz BG, Qualls C, Kloner RA, Laskey WK. Relation of Total and Cardiovascular Death Rates to Climate System, Temperature, Barometric Pressure, and Respiratory Infection. Am J Cardiol 2015; 116: 1290-7.

Taylor KE, Stouffer RJ, Meehl GA. An overview of CMIP5 and the experiment design. Bulletin of the American Meteorological Society 2012; 93: 485-498.

475 Tian L, Qiu H. Environmental factors and out-of-hospital cardiac arrest. Eur Heart J Qual Care $476 \quad$ Clin Outcomes 2017; 3: 97-98.

477 van Vuuren DP, Edmonds J, Kainuma M, Riahi K, Thomson A, Hibbard K, et al. The 478 van Vuuren DP, Stehfest E, den Elzen MGJ, Kram T, van Vliet J, Deetman S, et al. RCP2.6: exploring the possibility to keep global mean temperature increase below $2^{\circ} \mathrm{C}$. Climatic Change 2011b; 109: 95.

482 Vicedo-Cabrera AM, Sera F, Gasparrini A. Hands-on Tutorial on a Modeling Framework for 483 Projections of Climate Change Impacts on Health. Epidemiology 2019; 30: 321-329. 
Warszawski L, Frieler K, Huber V, Piontek F, Serdeczny O, Schewe J. The Inter-Sectoral Impact Model Intercomparison Project (ISI-MIP): project framework. Proc Natl Acad Sci U S A 2014; 111: 3228-32.

Watanabe S, Hajima T, Sudo K, Nagashima T, Takemura T, Okajima H, et al. MIROC-ESM 2010: model description and basic results of CMIP5-20c3m experiments. Geosci. Model Dev. 2011; 4: 845-872.

Watts N, Adger WN, Agnolucci P, Blackstock J, Byass P, Cai W, et al. Health and climate change: policy responses to protect public health. Lancet 2015; 386: 1861-914.

Wissenberg M, Lippert FK, Folke F, Weeke P, Hansen CM, Christensen EF, et al. Association of national initiatives to improve cardiac arrest management with rates of bystander intervention and patient survival after out-of-hospital cardiac arrest. JAMA 2013; 310: $1377-84$.

Wolf K, Schneider A, Breitner S, von Klot S, Meisinger C, Cyrys J, et al. Air temperature and the occurrence of myocardial infarction in Augsburg, Germany. Circulation 2009; 120: 73542.

Woodhouse PR, Khaw KT, Plummer M, Foley A, Meade TW. Seasonal variations of plasma fibrinogen and factor VII activity in the elderly: winter infections and death from cardiovascular disease. Lancet 1994; 343: 435-9.

Zhang B, Li G, Ma Y, Pan X. Projection of temperature-related mortality due to cardiovascular disease in beijing under different climate change, population, and adaptation scenarios. Environ Res 2018; 162: 152-159.

Zhang Y, Xiang Q, Yu Y, Zhan Z, Hu K, Ding Z. Socio-geographic disparity in cardiorespiratory mortality burden attributable to ambient temperature in the United States. Environ Sci Pollut Res Int 2019; 26: 694-705. 
508 Zhang Y, Yu C, Bao J, Li X. Impact of temperature on mortality in Hubei, China: a multi-county $509 \quad$ time series analysis. Sci Rep 2017; 7: 45093.

510 


\section{Figure legends}

512 Figure 1. The geographic distribution of the 47 Japanese prefectures and climate stations. The

513 colors represent different ranges of mean daily temperature during the study period.

515 Figure 2. Decadal temperature trends in Japan by scenario. The graph shows the projected

516 increase in temperature $\left({ }^{\circ} \mathrm{C}, \mathrm{GCM}\right.$-ensemble average), averaged by decade and climate change

517 scenario, compared to the current period (2010-2019).

519 Figure 3. Trends in heat-related and cold-related excess morbidity in Japan. The graph shows the 520 excess morbidity by decade attributed to heat and cold under three climate change scenarios

521 (RCP2.6, RCP4.5, and RCP8.5). Estimates are reported as GCM-ensemble mean decadal

522 fractions. The shaded areas represent $95 \%$ empirical confidence intervals (eCIs).

$523 \mathrm{RCP}=$ representative concentration pathway; GCM=general circulation model.

525 Figure 4. Temporal change in excess morbidity in Japan. The graph shows the difference in 526 excess morbidity by decade compared with 2010-2019 under three climate change scenarios 527 (RCP2.6, RCP4.5, and RCP8.5). Estimates are reported as GCM-ensemble means. The black 528 vertical segments represent $95 \%$ empirical CIs (eCIs) of net difference. RCP=representative 529 concentration pathway; GCM=general circulation model. 
530 Tables

531 Table 1. Heat-related, cold-related, and net excess morbidity (\%) with $95 \%$ eCI by period and

532 climate change scenario in Japan.

\begin{tabular}{|c|c|c|c|c|c|}
\hline \multirow{2}{*}{ Scenario } & \multirow{2}{*}{$\begin{array}{l}\text { Projected increase in } \\
\text { temperature }(2090- \\
2099 \text { vs } 2010-2019)\end{array}$} & \multirow{2}{*}{ Effect } & \multicolumn{3}{|c|}{ Period } \\
\hline & & & 2010-2019 & 2050-2059 & 2090-2099 \\
\hline \multirow[t]{3}{*}{$\mathrm{RCP} 2.6$} & $0.6(0.4,0.9)$ & Heat & $0.4(0.1,0.6)$ & $0.7(0.2,1.4)$ & $0.6(0.2,0.9)$ \\
\hline & & Cold & $19.9(-0.1,33.2)$ & $18.6(-0.9,31.9)$ & $18.9(-0.7,32.3)$ \\
\hline & & Net & - & $-1.0(-2.3,-0.1)$ & $-0.8(-1.9,0.1)$ \\
\hline \multirow[t]{3}{*}{$\mathrm{RCP} 4.5$} & $1.8(1.4,2.2)$ & Heat & $0.3(0.1,0.5)$ & $0.8(0.2,1.4)$ & $1.0(0.2,1.8)$ \\
\hline & & Cold & $20.1(0.2,33.4)$ & $17.6(-1.4,30.7)$ & $16.8(-1.8,29.8)$ \\
\hline & & Net & - & $-2.0(-3.1,-0.8)$ & $-2.6(-4.4,-0.8)$ \\
\hline \multirow[t]{3}{*}{ RCP6.0 } & $2.5(1.7,3.0)$ & Heat & $0.3(0.1,0.5)$ & $0.6(0.2,1.0)$ & $1.4(0.3,2.8)$ \\
\hline & & Cold & $20.3(0.3,33.8)$ & $18.2(-1.1,31.3)$ & $15.9(-2.1,28.5)$ \\
\hline & & Net & - & $-1.9(-3.1,-0.9)$ & $-3.4(-5.7,-1.0)$ \\
\hline \multirow[t]{3}{*}{ RCP8.5 } & $4.0(3.0,4.9)$ & Heat & $0.4(0.1,0.6)$ & $1.0(0.3,1.8)$ & $2.4(0.5,4.2)$ \\
\hline & & Cold & $19.9(-0.1,33.4)$ & $16.8(-1.8,29.5)$ & $13.8(-2.5,25.5)$ \\
\hline & & Net & - & $-2.5(-4.8,-0.5)$ & $-4.2(-8.3,-0.1)$ \\
\hline
\end{tabular}

533 Data on projected increase in temperature are average mean prefecture-specific temperature

534 (range) as GCM-ensemble. $\mathrm{RCP}=$ representative concentration pathway. GCM=general

535 circulation model. 


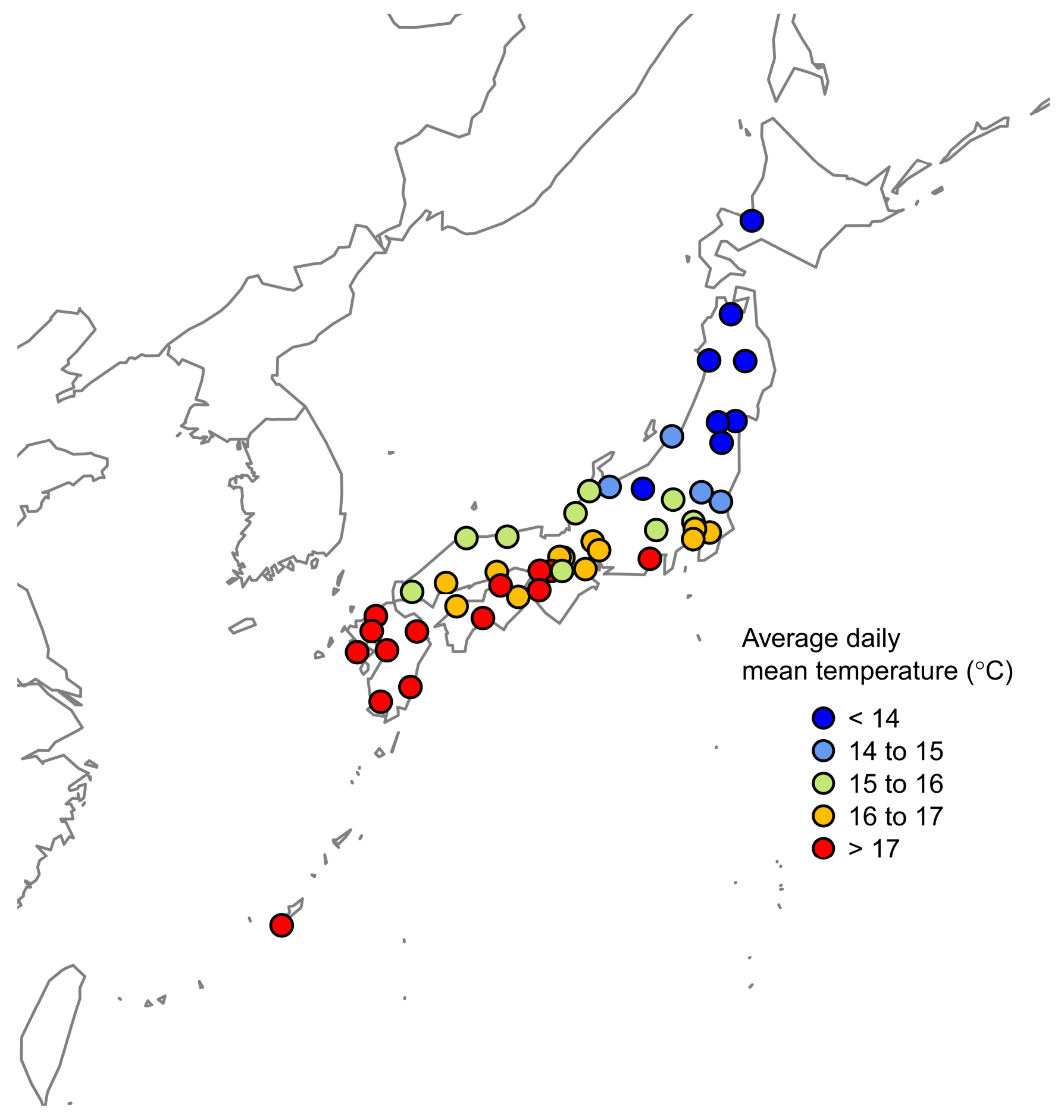

Figure 1 


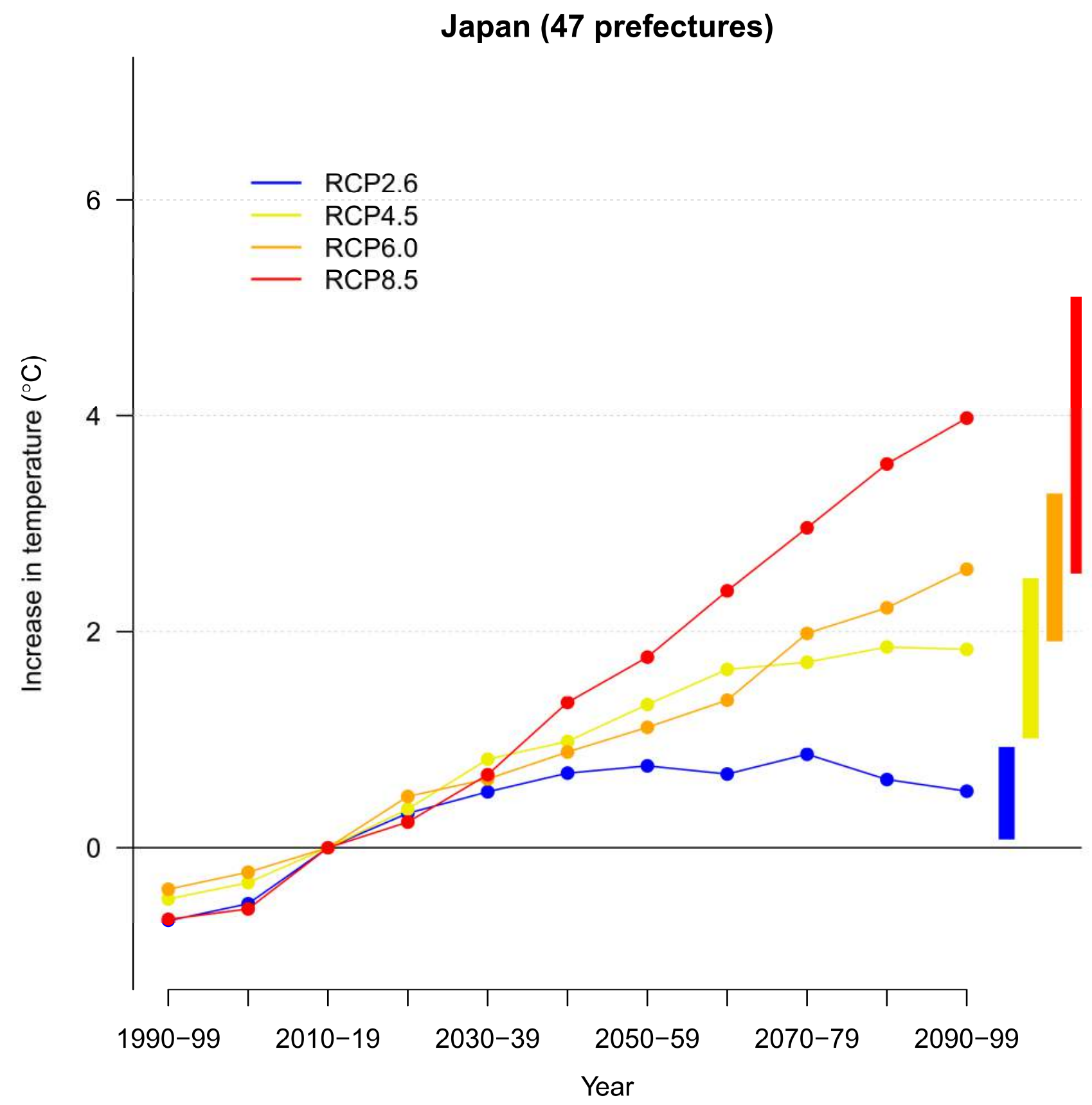

Figure 2 


\section{Japan (47 prefectures)}

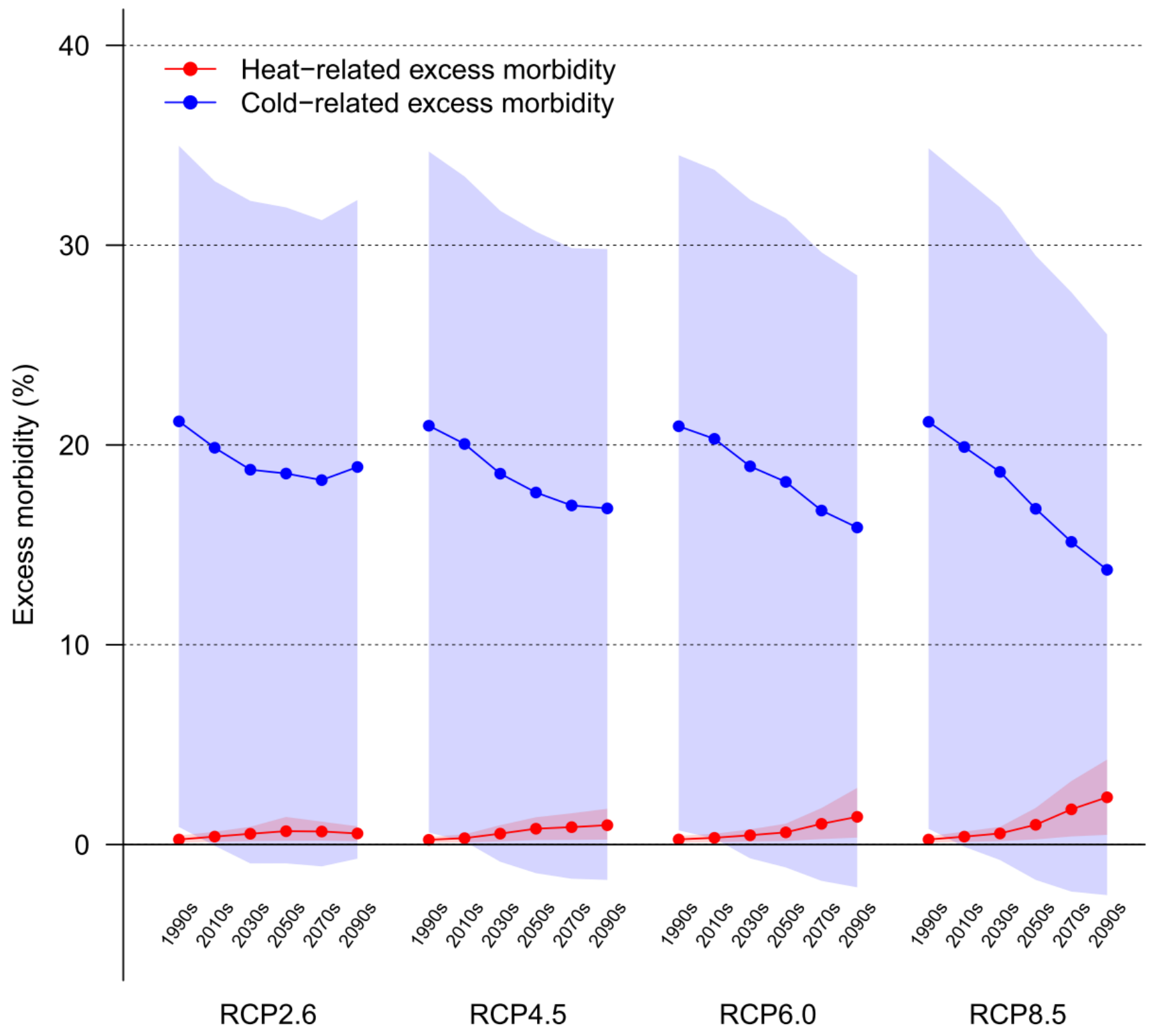

Figure 3 


\section{Japan (47 prefectures)}

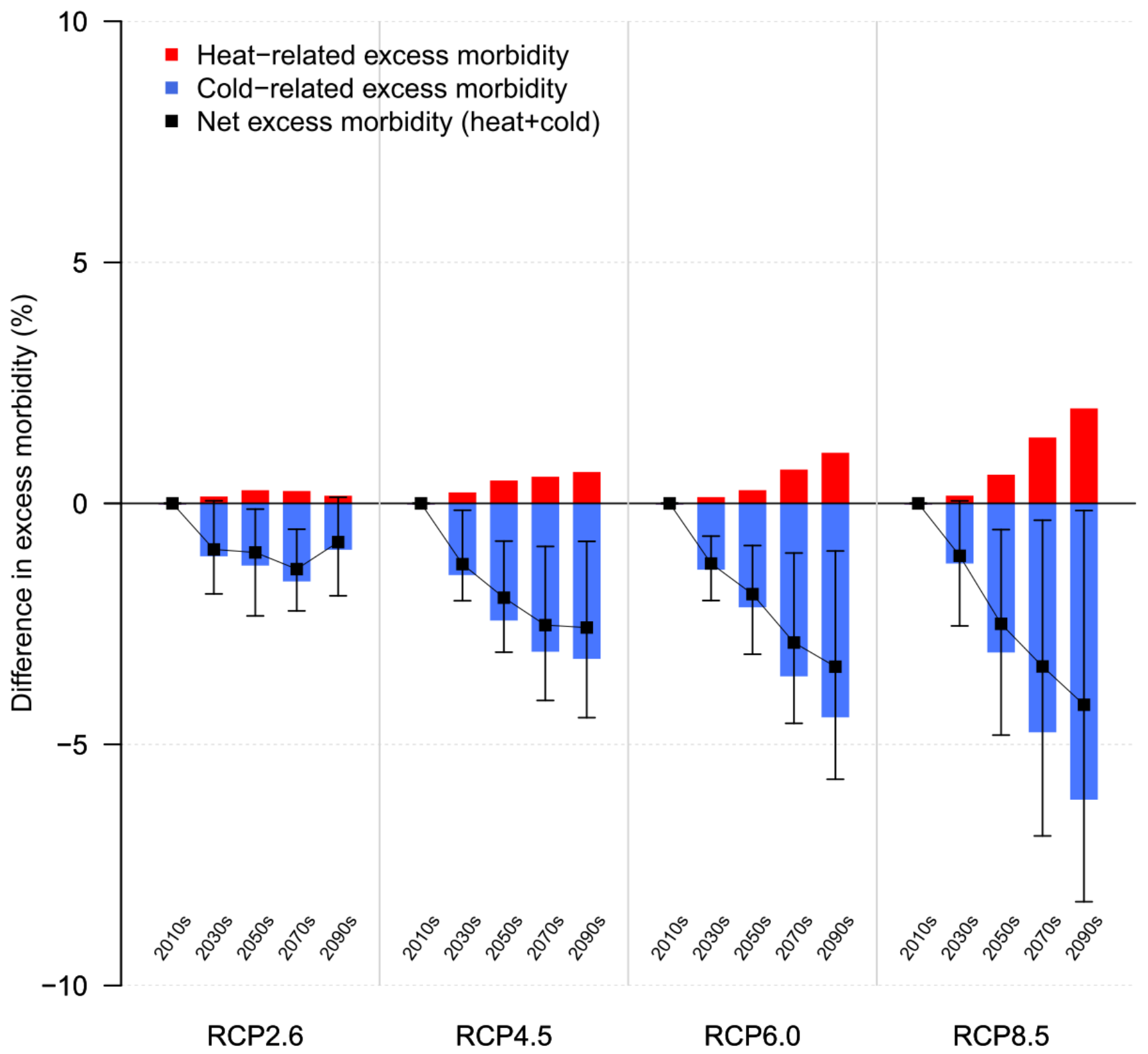

Figure 4 